\title{
STRATOSPHERIC POLLUTION RELATED ULTRAVIOLET RADIATION PHENOMENA
}

\author{
M. ACKERMAN \\ Institut d'Aéronomie Spatiale de Belgique, \\ 3, av. Circulaire, 1180-Bruxelles, Belgique
}

\begin{abstract}
Résumé. - Une revue concise des phénomènes ultraviolets qui jouent un rôle dans la pollution stratosphérique est présentée. Son but est de mettre en évidence les aspects principaux par des exemples récents. L'accent est placé sur les nouvelles données obtenues depuis sept ans au sujet du rayonnement ultraviolet solaire.
\end{abstract}

\begin{abstract}
A short review of ultraviolet phenomena related to stratospheric pollution is presented. Its purpose is to highlight major aspects with recent examples. The new data obtained on the solar ultraviolet radiation since seven years are emphasized.
\end{abstract}

1. Introduction. - Solar ultraviolet radiation plays a fundamental role in the formation of the stratosphere itself since it leads to the ozone photochemical formation from oxygen molecules dissociated below $242 \mathrm{~nm}$. Ozone in turn maintains the positive stratospheric temperature gradient versus altitude by absorbing solar energy in the ultraviolet in the upper stratosphere and earth energy in the infrared in the lower stratosphere. The combination of these delicate energy transfer processes associated with those related with carbon dioxyde and water vapour leads to the existence of the very characteristic stratospheric layer. This stable layer, not only limits the exchange of matter with the troposphere below but also limits by its ozone content the penetration of ultraviolet solar radiation of wavelengths smaller than $290 \mathrm{~nm}$ to the troposphere, down to the ground, protecting living organisms from too harsh radiations.

The spectral distribution of the number of photons available at various altitudes is governed by the atmospheric absorbers : molecular oxygen and ozone itself. The various photochemical processes proceed at various rates depending on the altitude and on the characteristic spectral response of the molecular species involved of which a survey has recently been published by Nicolet [1]. The photochemical processes have variable efficiencies depending on wavelength but also on temperature:

At wavelengths larger than $290 \mathrm{~nm}$, Rayleigh scattering and earth albedo effects play a role in the intensity spectral distribution of radiation available for photochemical processes in the troposphere and in the stratosphere, and also at ground level where its effects on living organisms is evident already in the visible range of the solar spectrum from the blue color of the sky.

Eventually ultraviolet radiation is used in the study of the stratosphere itself for remote sensing or in situ determinations of molecular species of which the ultraviolet spectra offer unique opportunities to measure them.

These various aspects of ultraviolet radiation phenomena will be briefly reviewed.

2. The solar flux. - Since the solar ultraviolet radiation is not observable from the ground at wavelengths shorter than $290 \mathrm{~nm}$ it has not been determined before the use of large balloons, rockets or satellites. In earlier times aeronomers had to use solar physics data based on observations at longer wavelengths to estimate the ultraviolet solar flux. Solar flux data based on rocket observations and published in 1961 by Detwiler, Garrett, Purcell and Tousey [2] for the wavelength range from $85 \mathrm{~nm}$ to $260 \mathrm{~nm}$ have been widely used thereafter. Satellite measurements performed by Parkinson and Reeves [3] showed that the flux from $140 \mathrm{~nm}$ to $180 \mathrm{~nm}$ has been previously overestimated. On the other hand Bonnet obtained evidence from rocket stigmatic spectra [4] for the abrupt change in limb darkening of the sun around $200 \mathrm{~nm}$ concurrent with an abrupt intensity change. This was confirmed by solar flux measurements performed from a balloon platform [5] in the $200 \mathrm{~nm}$ atmospheric window. This lead in 1971 to the publication of a new listing [6] of solar flux values from $116.3 \mathrm{~nm}$ to $730 \mathrm{~nm}$ presented in wavelength intervals compatible with the variation with wavelength of oxygen and ozone absorption cross sections. 
TABLE I

Solar ultraviolet measurements published since 1972

Authors

Broadfoot

Carver et al.

Ackerman-Simon

Nishi et al.

Rottman

Heroux-Swirbalus

Brueckner et al.

Samain-Simon

Kjeldseth Moe et al.

Ackerman

Simon

DeLuisi
Wavelengths

covered (nm)

210 to 320

143 to 162

121.6, 145 and 171

155 to 195

115 to 195

123 to 194

175 to 210

150 to 210

135 to 210

182 and 191

196 to 230

298.1 to 400.0

Vehicle
-
Rocket
$i d$.
$i d$.
$i d$.
$i d$.
$i d$.
$i d$.
$i d$.
$i d$.
Balloon + Rocket
Balloon
Ground

Reference

[7]

[8]

[9]

[10]

[11]

[12]

[13]

[14]

[15]

[16]

[17]

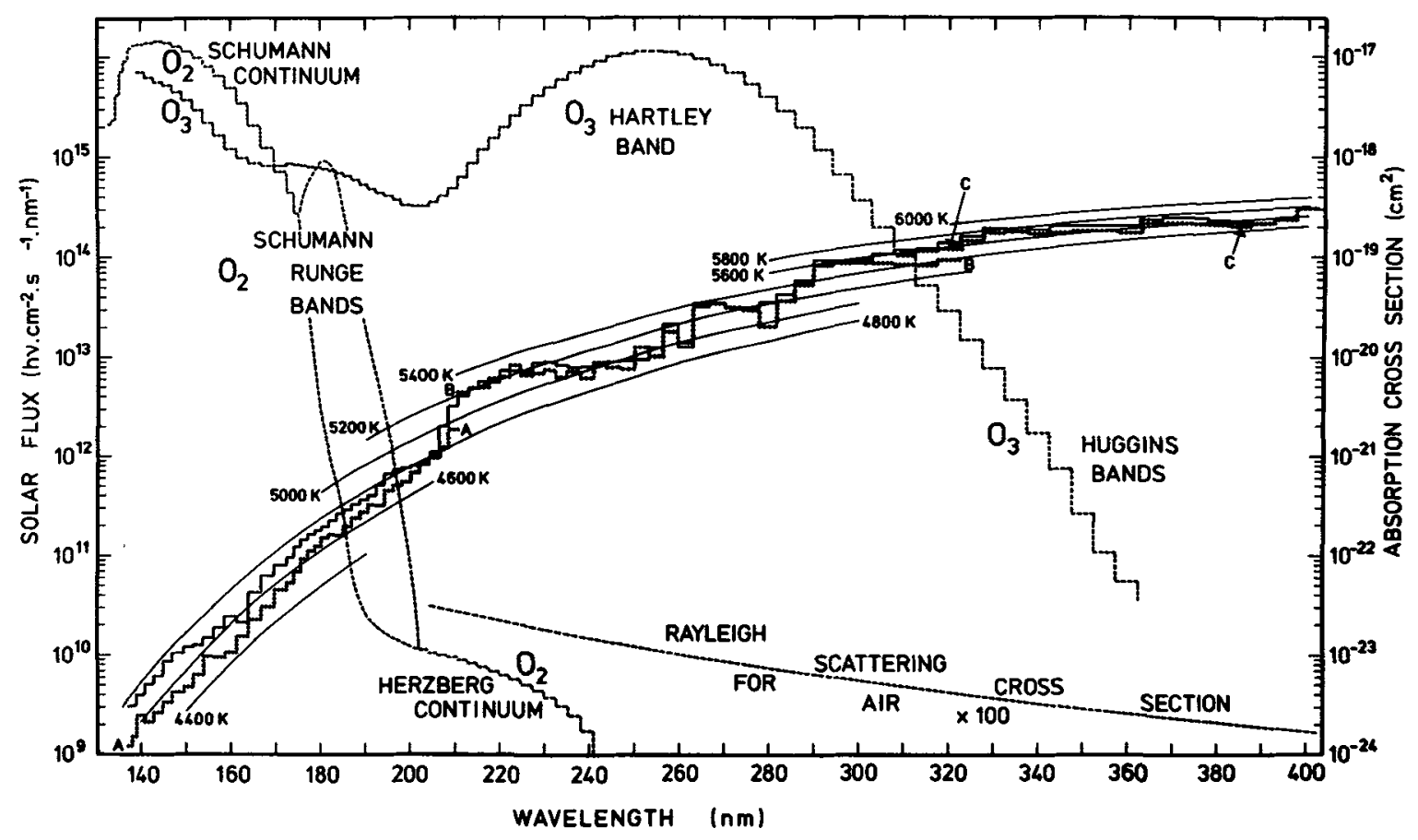

FIG. 1. - Ultraviolet solar flux from $140 \mathrm{~nm}$ to $400 \mathrm{~nm}$ based on the measurements performed by Kjeldseth Moe et al. [15], Broadfoot [7] and Arvesen et al. [21] which are respectively represented by the dotted histograms marked $\mathrm{A}$, B and C. The measurements made by Simon [17] in the $200 \mathrm{~nm}$ atmospheric window and taken into account in table II are not represented here for the sake of clarity. The values published by Ackerman in 1971 [6] are represented by the continuous histogram for the sake of comparison. Solar black body temperatures are indicated from $4400 \mathrm{~K}$ to $6000 \mathrm{~K}$. The absorption cross sections of $\mathrm{O}_{2}$ on $\mathrm{O}_{3}$ are also shown with the Rayleigh scattering cross section for air.

Much effort has been devoted since five years to the improvement of our knowledge of the solar spectrum which deserves to be taken into account. The various experimental data sets are indicated in table I. Extensive reviews on solar physics have also appeared [19, 20].

The solar flux values listed in reference [6] and mostly based on various Naval Research Laboratory data except for a narrow region around $200 \mathrm{~nm}$ are shown in figure 1 by the solid histogram. Part of them have been updated on the basis of reference [15] from 137 to 210.5 , of reference [17] from 210.5 to 227.3, of reference [7] from 227.3 to 307.7 and on reference [21] from 307.5 to 735.0 . The new values are inlso shown on figure 1 and are presented in table II where their ratios to the previous values are also given.

If some differences appear from $300 \mathrm{~nm}$ to $200 \mathrm{~nm}$ the largest changes occur at smaller wavelengths. 
TABLE II

Solar flux, $q^{\prime}(137 \mathrm{~nm}-730 \mathrm{~nm})$, at one astronomical unit per wavelength intervals and comparison with reference [6]

\begin{tabular}{|c|c|c|c|}
\hline $\begin{array}{l}\text { Interval } \\
\text { number } \\
\text { (Ref. [6]) }\end{array}$ & $\begin{array}{c}\text { Wavelength } \\
\text { interval } \\
(\mathrm{nm})\end{array}$ & $\left(\right.$ hy $\left.\mathrm{cm}^{\prime}-2 \cdot \mathrm{s}^{-1}\right)$ & $\begin{array}{c}\text { Ratio } \\
q^{\prime} / q \\
\text { (Ref. [6]) }\end{array}$ \\
\hline- & - & - & - \\
\hline 28 & $137.0-137.9$ & $1.09 \times 10^{9}$ & 0.398 \\
\hline 29 & $137.9-138.9$ & $1.51 \times 10^{9}$ & 0.487 \\
\hline 30 & $138.9-140.8$ & $4.69 \times 10^{9}$ & 0.617 \\
\hline 31 & $140.8-142.8$ & $4.20 \times 10^{9}$ & 0.416 \\
\hline 32 & $142.8-144.9$ & $5.49 \times 10^{9}$ & 0.422 \\
\hline 33 & $144.9-147.0$ & $6.97 \times 10^{9}$ & 0.383 \\
\hline 34 & $147.0-149.2$ & $9.33 \times 10^{9}$ & 0.400 \\
\hline 35 & $149.2-151.5$ & $1.08 \times 10^{10}$ & 0.406 \\
\hline 36 & $151.5-153.8$ & $1.45 \times 10^{10}$ & 0.500 \\
\hline 37 & $153.8-156.2$ & $2.31 \times 10^{10}$ & 0.642 \\
\hline 38 & $156.2-158.7$ & $2.38 \times 10^{10}$ & 0.501 \\
\hline 39 & $158.7-161.3$ & $2.74 \times 10^{10}$ & 0.428 \\
\hline 40 & $161.3-163.9$ & $4.01 \times 10^{10}$ & 0.730 \\
\hline 41 & $163-9-166.7$ & $6.39 \times 10^{10}$ & 0.537 \\
\hline 42 & $166.7-169.5$ & $8.48 \times 10^{10}$ & 0.482 \\
\hline 43 & $169.5-172.4$ & $1.31 \times 10^{11}$ & 0.565 \\
\hline 44 & $172.4-173.9$ & $7.83 \times 10^{10}$ & 0.544 \\
\hline 45 & $173.9-175.4$ & $1.04 \times 10^{11}$ & 0.568 \\
\hline 46 & $175.4-177.0$ & $1.45 \times 10^{11}$ & 0.620 \\
\hline 47 & $177.0-178.6$ & $1.75 \times 10^{11}$ & 0.668 \\
\hline 48 & $178.6-180.2$ & $1.96 \times 10^{11}$ & 0.681 \\
\hline 49 & $180.2-181.8$ & $2.42 \times 10^{11}$ & 0.771 \\
\hline 50 & $181.8-183.5$ & $2.75 \times 10^{11}$ & 0.722 \\
\hline 51 & $183.5-185.2$ & $2.70 \times 10^{11}$ & 0.609 \\
\hline 52 & $185.2-186.9$ & $3.33 \times 10^{11}$ & 0.673 \\
\hline 53 & 186.9 .188 .7 & $4.29 \times 10^{11}$ & 0.722 \\
\hline 54 & $188.7-190.5$ & $4.92 \times 10^{11}$ & 0.752 \\
\hline 55 & $190.5-192.3$ & $5.82 \times 10^{11}$ & 0.802 \\
\hline 56 & $192.3-194.2$ & $6.04 \times 10^{11}$ & 0.613 \\
\hline 57 & $194.2-196.1$ & $8.38 \times 10^{11}$ & 0.660 \\
\hline 58 & $196.1-198.0$ & $9.53 \times 10^{11}$ & 0.686 \\
\hline 59 & $198.0-200.0$ & $1.09 \times 10^{12}$ & 0.712 \\
\hline 60 & $200.0-202.0$ & $1.37 \times 10^{12}$ & 0.856 \\
\hline 61 & $202.0-204.1$ & $1.82 \times 10^{12}$ & 1.046 \\
\hline 62 & $204.1-206.2$ & $2.03 \times 10^{12}$ & 0.879 \\
\hline 63 & $206.2-208.3$ & $2.54 \times 10^{12}$ & 0.605 \\
\hline 64 & $208.3-210.5$ & $4.10 \times 10^{12}$ & 0.562 \\
\hline 65 & $210.5-212.8$ & $7.12 \times 10^{12}$ & 0.756 \\
\hline 66 & $212.8-215.0$ & $9.23 \times 10^{12}$ & 0.871 \\
\hline 67 & $215.0-217.4$ & $8.42 \times 10^{12}$ & 0.628 \\
\hline 68 & $217.4-219.8$ & $1.20 \times 10^{13}$ & 2.909 \\
\hline 69 & $219.8-222.2$ & $1.22 \times 10^{13}$ & 0.705 \\
\hline 70 & $222.2-224.7$ & $1.77 \times 10^{13}$ & 0.983 \\
\hline 71 & $224.7-227.3$ & $1.60 \times 10^{13}$ & 0.973 \\
\hline 72 & $227.3-229.9$ & $1.77 \times 10^{13}$ & 0.783 \\
\hline 73 & $229.9-232.6$ & $1.97 \times 10^{13}$ & 0.821 \\
\hline 74 & $232.6-235.3$ & $1.70 \times 10^{13}$ & 0.756 \\
\hline 75 & $235.3-238.1$ & $2.00 \times 10^{13}$ & 0.905 \\
\hline 76 & $238.1-241.0$ & $1.77 \times 10^{13}$ & 0.763 \\
\hline 77 & $241.0-243.9$ & $2.58 \times 10^{13}$ & 1.032 \\
\hline 78 & $243.9-246.9$ & $2.35 \times 10^{13}$ & 0.861 \\
\hline 79 & $246.9-250.0$ & $2.35 \times 10^{13}$ & 0.816 \\
\hline 80 & $250.0-253.2$ & $2.28 \times 10^{13}$ & 0.755 \\
\hline 81 & $253.2-256.4$ & $3.24 \times 10^{13}$ & 0.816 \\
\hline 82 & $256.4-259.7$ & $5.83 \times 10^{13}$ & 0.818 \\
\hline 83 & $259.7-263.2$ & $4.89 \times 10^{13}$ & 1.119 \\
\hline 84 & $263.2-266.7$ & $1.19 \times 10^{14}$ & 1.063 \\
\hline 85 & $266.7-270.3$ & $1.27 \times 10^{14}$ & 1.016 \\
\hline 86 & $270.3-274.0$ & $1.17 \times 10^{14}$ & 1.009 \\
\hline 87 & $274.0-277.8$ & $1.11 \times 10^{14}$ & 0.933 \\
\hline 88 & $277.8-281.7$ & $7.85 \times 10^{13}$ & 0.569 \\
\hline 89 & $281.7-285.7$ & $1.48 \times 10^{14}$ & 0.871 \\
\hline
\end{tabular}

TABLE II (continued)

Interval

(Ref. [6])

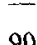

90

91

92
93

94

95

96

97

98

99

100
101

102

103

104

105

106

107

108

109

110

111

112

113

114

115

116

117

118

119

120

121

122

123

124

125

126

127

128

129

130

131

132

133

134

135

136

137

138

139

140

141

142

143

144

145

146

147

148

149

150

151

152

153

154

155

Wavelength interval

(nm)

285.7-289.9

289.9-294.1

294.1-298.5

298.5-303.0

303.0-307.7

$310.0( \pm 2.5)$

315.0

320.0

325.0

330.0

335.0

340.0

345.0

350.0

355.0

360.0

365.0

370.0

375.0

380.0

385.0

390.0

395.0

400.0

405.0

410.0

415.0

420.0

425.0

430.0

435.0

440.0

445.0

450.0

455.0

460.0

465.0

470.0

475.0

480.0

485.0

490.0

495.0

500.0

505.0

510.0

515.0

520.0

525.0

530.0

535.0

540.0

545.0

550.0

555.0

560.0

565.0

570.0

575.0

580.0

585.0

590.0

595.0

600.0

605.0

610.0 $\begin{array}{cc} & \text { Ratio } \\ q^{\prime} & q^{\prime} / q \\ \left(\mathrm{~h} v \cdot \mathrm{cm}^{-2} \cdot \mathrm{s}^{-1}\right) & \text { (Ref. }[6])\end{array}$
$2.23 \times 10^{14}$

0.879

$3.37 \times 10^{14} \quad 0.845$

$3.12 \times 10^{14} \quad 0.808$

$5.08 \times 10^{14} \quad 1.000$

$5.15 \times 10^{14} \quad 0.870$

$5.80 \times 10^{14} \quad 0.959$

$6.05 \times 10^{14} \quad 0.872$

$7.30 \times 10^{14} \quad 0.899$

$8.65 \times 10^{14} \quad 0.891$

$8.60 \times 10^{14} \quad 0.959$

$8.56 \times 10^{14} \quad 0.907$

$8.77 \times 10^{14} \quad 0.868$

$9.16 \times 10^{14} \quad 0.889$

$9.11 \times 10^{14} \quad 0.885$

$8.88 \times 10^{14} \quad 0.854$

$1.06 \times 10^{15} \quad 0.898$

$1.07 \times 10^{15} \quad 0.870$

$1.07 \times 10^{15} \quad 0.863$

$1.06 \times 10^{15} \quad 0.906$

$1.02 \times 10^{15} \quad 0.919$

$1.08 \times 10^{15} \quad 0.991$

$1.20 \times 10^{15} \quad 1.008$

$1.55 \times 10^{15} \quad 1.006$

$1.80 \times 10^{15} \quad 0.947$

$1.89 \times 10^{1 \mathrm{~s}} \quad 0.950$

$1.96 \times 10^{15} \quad 0.985$

$1.96 \times 10^{1 \mathrm{~s}} \quad 0.970$

$1.88 \times 10^{15} \quad 0.935$

$1.81 \times 10^{15}-0.933$

$1.92 \times 10^{15} \quad 0.970$

$2.13 \times 10^{15} \quad 0.947$

$2.25 \times 10^{15} \quad 0.941$

$2.33 \times 10^{15} \quad 0.940$

$2.41 \times 10^{15} \quad 0.968$

$2.44 \times 10^{15} \quad 0.984$

$2.43 \times 10^{15} \quad 0.972$

$2.45 \times 10^{15} \quad 0.961$

$2.52 \times 10^{15} \quad 0.966$

$2.54 \times 10^{15} \quad 0.981$

$2.42 \times 10^{15} \quad 0.984$

$2.42 \times 10^{15} \quad 0.992$

$2.49 \times 10^{15} \quad 0.984$

$2.47 \times 10^{15} \quad 0.996$

$2.50 \times 10^{15} \quad 1.004$

$2.53 \times 10^{15} \quad 1.012$

$2.48 \times 10^{15} \quad 1.021$

$2.42 \times 10^{15} \quad 0.996$

$2.49 \times 10^{15} \quad 0.988$

$2.56 \times 10^{15} \quad 0.992$

$2.57 \times 10^{15} \quad 0.973$

$2.57 \times 10^{15} \quad 0.963$

$2.59 \times 10^{15} \quad 0.959$

$2.61 \times 10^{15} \quad 0.974$

$2.59 \times 10^{15} \quad 0.974$

$2.58 \times 10^{15} \quad 0.970$

$2.62 \times 10^{15} \quad 0.981$

$2.66 \times 10^{15} \quad 0.996$

$2.70 \times 10^{15} \quad 1.004$

$2.75 \times 10^{15} \quad 1.015$

$2.73 \times 10^{15} \quad 1.007$

$2.72 \times 10^{15} \quad 1.004$

$2.71 \times 10^{15} \quad 0.996$

$2.71 \times 10^{15} \quad 0.996$

$2.72 \times 10^{15} \quad 1.004$

$2.74 \times 10^{15} \quad 1.015$ 
TABLE II (continued)

$\begin{array}{cccc}\begin{array}{c}\text { Interval } \\ \text { number } \\ \text { (Ref. [6]) }\end{array} & \begin{array}{c}\text { Wavelength } \\ \text { interval } \\ (\mathrm{nm})\end{array} & \begin{array}{c}q^{\prime} \\ \left(\mathrm{h} v . \mathrm{cm}^{-2} \cdot \mathrm{s}^{-1}\right)\end{array} & \begin{array}{c}\text { Ratio } \\ q^{\prime} / q \\ \text { (Ref. [6]) }\end{array} \\ 156 & 615.0 & - & - \\ 157 & 620.0 & 2.71 \times 10^{15} & 1.004 \\ 158 & 625.0 & 2.69 \times 10^{15} & 0.996 \\ 159 & 630.0 & 2.70 \times 10^{15} & 1.000 \\ 160 & 635.0 & 2.69 \times 10^{15} & 1.007 \\ 161 & 640.0 & 2.69 \times 10^{15} & 1.007 \\ 162 & 645.0 & 2.66 \times 10^{15} & 1.011 \\ 163 & 650.0( \pm 5.0) & 3.95 \times 10^{15} & 1.004 \\ 164 & 660.0 & 5.52 \times 10^{15} & 1.000 \\ 165 & 670.0 & 5.33 \times 10^{15} & 1.057 \\ 166 & 680.0 & 5.37 \times 10^{15} & 1.029 \\ 167 & 690.0 & 5.18 \times 10^{15} & 1.018 \\ 168 & 700.0 & 5.29 \times 10^{15} & 1.050 \\ 169 & 710.0 & 5.11 \times 10^{15} & 1.024 \\ 170 & 720.0 & 5.04 \times 10^{15} & 1.020 \\ 171 & 730.0 & 5.03 \times 10^{15} & 1.027\end{array}$

It should be kept in mind that here the basic observations [15], which are in general agreement with all relevant work indicated in table $I$, were performed selectively on a non-active region of the sun. They are thus likely to represent minimum values.

The visible part of the spectrum contributes the most to the solar constant. The last discussion on the subject has been recently published [22] giving a value equal to $1.972 \mathrm{cal} \mathrm{cm}^{-2} \mathrm{~min}^{-1}$.

3. Attenuation of solar radiation. - 3.1 MOLECULAR OXYGEN. - The $\mathrm{O}_{2}$ molecules are attenuating the solar ultraviolet radiation and photodissociate leading to atomic oxygen and subsequently to ozone. Two spectral regions have to be considered in the stratosphere. From the dissociation limit at $242 \mathrm{~nm}$ to $200 \mathrm{~nm}$ the Herzberg continuum is now rather well known $[23,24,25]$ as well as the absorption by $\mathrm{O}_{4}[26]$. At wavelengths shorter than $200 \mathrm{~nm}$ the predissociated lines of the Schumann-Runge bands add some complexity to the atmospheric models due to the large variations of the absorption cross section from the center to the wings of the lines.

The most recent spectroscopic measurements of the bands have been performed in 1970 [27] in absorption and in 1975 in emission in this latter case up to $v^{\prime \prime}$ levels $=28$ have been involved in the observed spectra [28]. Several theoretical studies have appeared since then on their fine structure [29], the knowledge of which could still be improved by new high resolution measurements. Their predissociation has been extensively studied [30] and many aspects remain unclear indicating there also the possibilities of new measurements on various isotopic combinations. Very recently, an ab initio vibrational analysis has lead to the conclusion that predissociation of all Schumann-Runge bands from 0-0 to $13-0$ as deduced from experimental work [23] could be theoretically explained [31].
The attenuation of solar ultraviolet radiation by $\mathrm{O}_{2}$ in the S-R bands is of crucial importance for atmospheric modelling since many species are photodissociated in their wavelength range in addition to $\mathrm{O}_{2}$ itself : $\mathrm{NO}, \mathrm{H}_{2} \mathrm{O}, \mathrm{CO}_{2}, \mathrm{HCl}, \mathrm{HNO}_{3}$, halocarbons, etc. The most accurate procedure to determine the dissociation coefficients is to compute line by line the absorption versus altitude, taking into account, the atmospheric temperature, the solar elevation angles depending on times of the day, seasons and latitudes. This has been done in a few cases and only for simplified geometries by Kockarts [32] for $\mathrm{O}_{2}$ and $\mathrm{H}_{2} \mathrm{O}$ and by Cieslik and Nicolet [33] for NO. In this latter case where predissociated NO bands interfere with the $\mathrm{S}-\mathrm{R}$ bands the problem becomes rather heavy to be treated, particularly if the high resolution solar spectrum is considered [16]. Due to the complexity of the computations in atmospheric models where chemical kinetics rate constants and air motion have to be dealt with, several authors have attempted to parametrize the attenuation in the S-R bands of atmospheric $\mathrm{O}_{2}[34,35,36,37,38,39]$.

At wavelengths shorter than $175 \mathrm{~nm}$, molecular oxygen absorbs the solar radiation in the thermosphere at altitudes larger than $90 \mathrm{~km}$. At the maximum of the Schumann continuum (about $144 \mathrm{~nm}$ ) and at the stratopause $(50 \mathrm{~km})$ an optical depth about equal to unity is reached over a pathlength of 0.3 meter.

3.2 Ozone. - A measurable [40, 41, 42] ozone absorption begins below $360 \mathrm{~nm}$ in the ultraviolet. The Huggins bands are followed by the Hartley band below $310 \mathrm{~nm}$ with a maximum at $255 \mathrm{~nm}$. A minimum of absorption appears at $202 \mathrm{~nm}$. This broad structure, combined with the absorption by $\mathrm{O}_{2}$ in the S-R bands leads to the formation of an atmospheric window letting the solar ultraviolet photons to reach the middle stratosphere $(30 \mathrm{~km})$ while a unit vertical optical depth occurs at $45 \mathrm{~km}$ at $255 \mathrm{~nm}$.

3.3 ArR. - Even if Rayleigh scattering cross sections [43] are small (Fig. 1), the redistribution of the ultraviolet photons by scattering plays a role on the photochemical processes taking place at wavelengths as short as $200 \mathrm{~nm}$ in the atmosphere as well as on the total amount of radiation reaching the ground near $300 \mathrm{~nm}$. In the latter case, if ozone absorption in the Huggins bands is the controlling factor aerosols intervene in the processes. The problem has been schematically illustrated [16] and has been studied in detail by various authors $[44,45]$ due to its importance on biological effects of solar ultraviolet radiation reaching the ground.

The earth albedo has also to be taken into account as well as in the evaluation of the photodissociation coefficients of various chemically active molecules when Rayleigh scattering is considered. In this case detailed evaluations are due to several authors $[46,47$, $48]$ and show that the accuracy of model calculations of the stratospheric composition relies on the consi- 
deration of scattering effects on the photodissociation of $\mathrm{NO}_{2}, \mathrm{O}_{3}, \mathrm{~N}_{2} \mathrm{O}, \mathrm{HNO}_{3}$ etc.

4. Photodissociation. - A basic term in stratospheric photochemical modelling is the photodissociation coefficient $j$ which can be expressed in photon. molecule ${ }^{-1} \mathrm{~s}^{-1}$ by

$$
j=q_{z}^{\prime} \varphi \sigma
$$

$q_{z}^{\prime}$ being the number of solar photon available at one moment and one geographic location per $\mathrm{cm}^{2}$ and per second at an altitude $z, \sigma$ the absorption cross section expressed in $\mathrm{cm}^{2}$ molecule ${ }^{-1}$ and $\varphi$ the quantum yield for the process under consideration.

The determination of $\sigma$ implies most of the time to measure the strength of continua. Even if this task does not look very appealing, new measurements often give surprising results since the data usually available have been obtained several decades ago and since the techniques and the availability of very pure substances have been both greatly improved. As an example, recent measurements of the absorption cross section of $\mathrm{N}_{2} \mathrm{O}$ [49] have shown that contrarily to the indication by older experiments the molecule does not absorb below $320 \mathrm{~nm}$ but below $260 \mathrm{~nm}$. The implication of this observation on the nitrogen cycle is remarkable since photodissociation of nitrous oxyde in the troposphere at $300 \mathrm{~nm}$ has been up to now the only sink considered for this molecule.

A more recent example concerns $\mathrm{CH}_{4}$. Methane was considered to present appreciable absorption at least up to $165 \mathrm{~nm}$ while new measurements [50] indicate a cross section value 200 times smaller than previously published at $147 \mathrm{~nm}$ with practically no absorption at wavelengths larger than $155 \mathrm{~nm}$. This finding combined with new methane measurements [51] showing a very low abundance of $\mathrm{CH}_{4}$ in the upper stratosphere indicates that this species is totally under chemical control in the earth atmosphere without any direct action of the solar UV radiation.

Temperature variations of absorption cross section may have some importance when band absorption is under consideration. This aspect is important for the Schumann-Runge bands [23]. The $\mathrm{NO}_{2}$ extinction coefficient is an other example [52]. The ozone absorption cross section is also known to vary with temperature [41].

The quantum yield for photodissociation is usually taken equal to unity. However, at the energy threshold of a specific process and particularly when the molecule involved is capable of storing and exchanging appreciable amounts of internal energy within the reaction path, important effects occur. This is the case for the formation of $\mathrm{O}{ }^{1} \mathrm{D}$ atoms by photolysis of ozone. In this case the quantum yield can vary from
0.25 to 0.5 at $313 \mathrm{~nm}$ over the stratospheric temperature range [53].

The halocarbons, many of which have apparently no sink in the troposphere, are photodissociated in the stratosphere, generating chlorine atoms capable of modifying the ozone balance [54]. Such substances absorb UV solar radiation at wavelengths shorter than $300 \mathrm{~nm}$ being protected by ozone in the low stratosphere. For many of them the knowledge of the penetration of the solar radiation in the SchumannRunge bands of $\mathrm{O}_{2}$ has to be determined and in addition their absorption cross section is sensitive to temperature variations [55].

5. Stratospheric species analysis in the ultraviolet. Stratospheric atoms and molecules are detected and their abundances measured on the basis of their molecular spectra. Ozone is routinely measured by the method developped by Dobson and Goetz (see Ref. [56] and several articles in the same volume) which is based on differential absorption measurements in the Huggins bands. The observation from satellites take place since several years on the basis of the observation of the backscattered UV radiation from 255 to $340 \mathrm{~nm}$ [57].

The $306 \mathrm{~nm} \mathrm{OH}$ band has been used by several groups to measure this radical ; by means of a fluorescence chamber dropped from a balloon gondola at $40 \mathrm{~km}$ altitude [58] and of lasers operated from an aircraft [59]. The total atmospheric content of $\mathrm{OH}$ has also been measured from the ground by the observation [60] of the absorption spectrum using the sun as a source. Absorption measurement with a tunable dye laser have also lead to $\mathrm{OH}$ determinations in the troposphere [61, 62]. Again by excitation and observation of the fluorescence in a falling chamber atomic oxygen has been observed in the stratosphere at the ${ }^{\overline{3}} \mathrm{P}-{ }^{3} \mathrm{~S}$ transition at $130.4 \mathrm{~nm}$ [63]. On the basis of the same atomic resonance fluorescence method, $\mathrm{Cl}$ atoms have been observed in the stratosphere at $118.8 \mathrm{~nm}$ as well as $\mathrm{ClO}$ through the formation of $\mathrm{Cl}$ by in situ stimulated reaction with NO [64].

6. Conclusion. - It is obvious, even from a noncomprehensive review as this one, that much progress has been made in recent years on stratospheric research on the basis of the investigation and of the application of ultraviolet phenomena. The large amount of work devoted to the stratosphere has been largely stimulated by the environmental concerns about the possibility of the artificial modification of the ozone balance. The consciousness of the wealth and of the importance of the natural phenomena occurring in the stratosphere has greatly benefitted from this effort which has also indicated that much remains to be done. 


\section{References}

[1] Nicolet, M., Rev. Geophys. Space Phys. 13 (1975) 593.

[2] Detwiler, C. R., Garrett, D. L., Purcell, J. D. and Tousey, R., Ann. Géophys. 17 (1961) 9.

[3] Parkinson, W. H. and Reeves, E. M., Sol. Phys. 10 (1969) 342.

[4] BONNET, R. M., Space Res. 7 (1968) 458.

[5] Ackerman, M., Frimout, D. and Pastiels, R., Ciel et Terre 84 (1968) 408.

[6] Ackerman, M., in Mesospheric Models and Related experiments, edited by G. Fiocco (D. Reidel, Dordrecht, Holland) 1971, pp. 149-159.

[7] BroadFoot, A. L., Astrophys. J. 173 (1972) 681.

[8] Carver, J. H., Norton, B. H., Lockey, G. W. and Rofe, B., Sol. Phys. 27 (1972) 347.

[9] Ackerman, M. and Simon, P., Sol. Phys. 30 (1973) 345.

[10] Nishi, K., Higashi, K., Yamagushi, A. and Suemoto, Z., Bull. Inst. Sp. Aeronaut. Sci. Univ. Tokyo 10 (1974) 611.

[11] Rottman, G. J., Trans. Am. Geophys. Union 56 (1974) 1157.

[12] Heroux, L. and Swirbalus, R. A., J. Geophys. Res. 81 (1976) 436.

[13] Brueckner, G. E., Bartoe, J.-D. F., Kueldseth Moe, O. and VAN Hossier, M. E., Astrophys. J. 209 (1976) 935.

[14] Samain, D. and Simon, P. C., Sol. Phys. 49 (1976) 33.

[15] KJeldseth Moe, O., van Hoosier, M. E., Bartoe, J.-D. F. and BRUECKNeR, G. E., NRL Report 8056, Naval Research Laboratory, Washington, D.C. (1976).

[16] Ackerman, M., Can. J. Chem. 52 (1974) 1505.

[17] Simon, P., in Proceedings of the Third Conference on Climatic Impact Assessment Program, DOT-TSC-OST-74-15 (1974).

[18] Deluisi, J. J., J. Geophys. Res. 80 (1975) 345.

[19] Smith, E. V. P. and GotTlieb, D. M., Space Sci. Rev. 16 (1974) 771.

[20] Vernazza, J. E., Avrett, E. H. and Loeser, R., Astrophys. J. Suppl. 30 (1976) 1.

[21] Arvesen, J. C.. Griffen, R. N. and Pearson Jr., B. B., Appl. Opt. 8 (1969) 2215.

[22] Forgan, B. W., Appl. Opt. 16 (1977) 1628.

[23] Ackerman, M., Binume, F. and Kockarts, G., Planet. Space Sci. 18 (1970) 1639.

[24] Hudson, R. D., Can. J. Chem. 52 (1974) 1465.

[25] Hudson, R. D., Rev. Geophys. Space Phys. 9 (1971) 306.

[26] Shardanand, Phys. Rev. 18 (1969) 5.

[27] Ackerman, M. and Biaume, F., J. Mol. Spectrosc. 35 (1970) 73.

[28] Creek, D. M. and Nicholls, R. W., Proc. R. Soc. London A 341 (1975) 517.

[29] Bergeman, T. H. and Wofsy, S. C., Chem. Phys. Lett. 15 (1972) 104.

[30] Julienne, P. S. and Krauss, M., J. Mol. Spectrosc. 56 (1975) 270.

[31] Buenker, R. J., Peyerimhoff, S. D. and Peric, M., Chem. Phys. Lett. 42 (1976) 383.

[32] KockARTs, G., in Mesospheric models and related experiments, Fiocco ed. (Reidel Publ. Cy. Dordrecht) 1971

[33] Creslik, S. and Nicolet, M., Planet. Space Sci. 21 (1973) 925.

[34] Hudson, R. D. and Mahle, S. H., J. Geophys. Res. 77 (1972) 2902.
[35] FAng, T.-M., Wofsy, S. C. and Dalgarno, A., Planet. Space Sci. 22 (1974) 413.

[36] Park, J. H., J. Atmos. Sci. 31 (1974) 1893.

[37] Muramatsu, H., Papers in Met. Geophys. 26 (1975) 219.

[38] Kockarts, G., Planet. Space Sci. 24 (1976) 589.

[39] Shimazaki, T., Ogawa, T. and Farrell, B. C., NASA Technical Note TN D-8399-Washington DC (1977).

[40] Inn, E. C. Y. and Tanaka, Y., J. Opt. Soc. Am. 43 (1953) 870.

[41] Vigroux, E., Contribution à l'étude expérimentale de l'ozone (Masson et Cie, Paris) 1953.

[42] Vigroux, E., Ann. Géophys. 25 (1969) 169.

[43] Penndorf, R., J. Opt. Soc. Am. 47 (1957) 476.

[44] Shettle, E. P. and Green, A. E. S., Appl. Opt. 13 (1974) 1567.

[45] Sundaraman, N., St. John, D. E. and Venkateswaren, S. V., Solar ultraviolet radiation received at the earth's surface under clear and cloudless conditions, DOT-TST-75-101, U.S. Department of Transportation, Washington DC (1975).

[46] Luther, F. M. and Gelinas, R. J., J. Geophys. Res. 81 (1976) 1125.

[47] Callis, L. B., Ramanathan, V. and Boughner, R. E., Proceedings of the Fourth Conference on the Climatic Impact Assessment Program, DOT-TSC-OST-75-38, U.S. Department of Transportation, Washington D.C. (1975).

[48] Isaksen, I. S. A., Midtbo, K., Sunde, J. and Crutzen, P., Report $\mathrm{n}^{\circ}$ 20, Institutt for Geofysikk Universiteteb $\mathrm{i}$ Oslo (1976).

[49] Johnston, H. S. and Selwyn, G., G.R.L. 2 (1975) 549.

[50] Mount, G. H., Warden, E. S. and Moos, H. W., Ap. J. 214 (1977) L47.

[51] Ackerman, M., Frimout, D. and Muller, C., Aeronomica Acta A 180 (1977) to appear in Pageoph.

[52] Bass, A. M., Ledford, A. E. and Laufer, A. H., J. Res. Nat. Bur. Stand. 80A (1976) 143.

[53] Kajimoto, O. and Cvetanovic, R. J., Chem. Phys. Lett. 37 (1976) 533.

[54] Rowland, F. S. and Molina, M. J., Rev. Geophys. Space Phys. 13 (1975) 1.

[55] Chou, C. C., Smith, W. S., Vera Ruis, H., Moe, K., CresCEnTini, G., Molina, M. J. and Rowland, F. S., $J$. Phys. Chem. 81 (1977) 286.

[56] Dutsch. H. U., Pageoph 106108 (1973) 915.

[57] Heath, D. F.. Mateer, C. L. and Krueger, A. J., Pageoph 106-108 (1973) 1238.

[58] Anderson, J. G., G.R.L. 3 (1976) 165.

[59] Davis, D. D., Heaps, W. and McGee, T., G.R.L. 3 (1976) 331.

[60] BuRnETT, C. R., G.R.L. 3 (1976) 319.

[61] Wang, C., Davis, L. I., Wu, C. H., JaPer, S., NikI, H. and Weinstock, B., Science 189 (1975) 797.

[62] Perner, D., Ehhalt, D. H., Patz, H. W., Platt, U., Roth, E. P. and Volz, A., G.R.L. 3 (1976) 466.

[63] ANDERSON, J. G., G.R.L. 2 (1975) 231.

[64] Anderson, J. G., Science, in the press. 